\title{
Critical care management in burns: A review of current evidence and guidelines -Part 1
}

\author{
Umesh Jayarajah, Oshan Basnayake, Gayan Ekanayake \\ Plastic and Reconstructive Surgery, National Hospital of Sri Lanka, Colombo, Sri Lanka
}

Keywords: Burns; severe burns; critical care; burns resuscitation; fluid resuscitation; review

\begin{abstract}
Recent literature on the management of critically ill patients have altered the beliefs and clinical behaviours, questioning many dogmas that were practiced without much evidence. The critical care in a severely burn-injured patient requires special attention in resuscitation, haemodynamic monitoring, management of complications, organ support and determinants of outcome. The goal of resuscitation is to maintain intravascular volume and tone while correcting the reversible changes in altered physiology, aided by early debridement of burned tissue and elimination of the source of physiological derangement. Practitioners should target resuscitation based on goal-directed therapy using noninvasive markers of cardiac output. The management requires the input of a multi-disciplinary team to achieve critical care and early surgical intervention and management of complications and organ support.
\end{abstract}

\section{Introduction}

Recent literature on the management of critically ill patients have altered the beliefs and clinical behaviours, questioning many dogmas that were practiced without much evidence [1]. Furthermore, the fundamental understanding of critical care in terms of fluid management, haemodynamic monitoring, management of acute respiratory distress syndrome (ARDS), organ support and nutrition support are changing [1]. The goal of resuscitation is to maintain intravascular volume and tone while correcting the reversible changes in altered physiology, aided by early debridement of burned tissue and elimination of the source of physiological derangement. The definition of severe burns is based on the surface area $(20 \%$ excluding superficial burns), presence of inhalational or electrical injury, patients' age and comorbidities [2]. The critical period in severe burns is usually transient, lasting for few days. However, may include intermittent episodes of deterioration based on burn related complications. This narrative review focuses on the contemporary literature, on the critical care of severe burns once the patient has been stabilised after the initial injury. The review consists of two parts and the first part focusses on fluid resuscitation, goaldirected fluid therapy, haemodynamic monitoring and coagulopathy in severe burns. The second part describes aspects such as thromboprophylaxis, role of suppressing hypermetabolism, glycaemic control, nutritional support, sepsis and infection control, management of inhalational injuries, surgical debridement, pain management and palliative care in severe burns.

\section{Methods}

We performed a literature search on PubMed and Google Scholar, and looked for published original articles, review articles and guidelines on critical care management in burns, up to November 2019. Our search was limited to articles in English. Correspondence, dissertations and unpublished materials were not considered. The information were summarised and presented qualitatively (narratively) under subheadings.

\section{Contents:}

Fluid resuscitation in severe burns

Goal-directed fluid therapy and Haemodynamic monitoring

Evidence on choice of fluid for resuscitation

Management of coagulopathy in severe burns

Thromboprophylaxis in burns

The role of suppressing hypermetabolism in severe burns

Glycaemic control in severe burns

Nutritional support in severe burns

Sepsis and infection control in burns

Management of inhalational injuries and acute respiratory distress syndrome (ARDS)

Early surgical debridement and soft tissue cover

Pain management in severe burns

Palliative care in severe burns

Correspondence: Umesh Jayarajah

E-mail: umeshe.jaya@gmail.com

(i) https://orcid.org/0000-0002-0398-5197

Received: 11-01-2020 Accepted: 29-08-2020

DOI: http://doi.org/10.4038/sljs.v38i2.8664

The Sri Lanka Journal of Surgery 2020; 38(2): 50-56 


\section{Fluid resuscitation in severe burns}

The patients with severe burns receive a large volume of fluid in the first 24 hours compared with any other trauma patients due to the pathophysiological processes involved. The initial burn shock results due to a combination of hypovolaemic shock and cell shock. In addition to the local increase in vascular permeability in affected tissue, the inflammatory mediators such as Nuclear factor $\kappa \mathrm{B}$, tumor necrosis factor (TNF- $\alpha$ ) and other cytokines released by burned tissue causes sequestration of leucocytes and other inflammatory cells. These cells act as a major source of proinflammatory mediators and initiate a major systemic inflammatory response syndrome, increasing the vascular permeability in both the affected and healthy tissue throughout the body [3]. The cascade of events leads to increased fluid shift from the intravascular compartment to the interstitial space causing oedema, haemoconcentration and hypovolaemia. In addition, the cytokine storm produced by the inflammatory response results in decreased vascular resistance due to vasodilation and decreased cardiac contractility, contributing to shock. Furthermore, the severity of the inhalation injury also impacts the fluid requirements and the prognosis.

The Parkland formula is widely used for initial fluid resuscitation in the burns patient. According to the American Burn Association guidelines the formula was revised to 2-4 $\mathrm{ml}$ of Ringer's lactate (RL) solution per kilogram of weight per percentage of burned body surface area in adults [4]. The primary objectives of fluid resuscitation are preserving and restoring tissue perfusion and preventing ischaemia. However, this is challenging due to the worsening oedema and transvascular displacement of fluids during resuscitation $[5,6]$. Although the Parkland formula is utilised, the volume of fluid has to be adjusted according to the urinary output and other parameters leading to considerable variations in the fluid administered. A study by Ete et al has shown significant differences in the fluid administered based on urine output and the fluid calculated by Parkland formula [7]. The imprecise body surface area calculations and variations in fluid shift may contribute to this discrepancy. Suboptimal resuscitation leads to increase of burn depth and prolongs the shock period resulting in higher mortality $[1,6]$.

\section{Determining the initial amount of fluid therapy}

As the volume of fluid during resuscitation is proportional to the extent of burns, the severe burns are the most challenging to treat [8]. In many units, severe burns is arbitrarily categorised as involvement of at least $20 \%$ of body surface area excluding superficial burns because, strict monitoring and intravenous fluid resuscitation is needed in such patients [9]. In severe burns, selecting the appropriate choice of fluid is essential in determining the outcome and incorrect replacement may lead to a series of complications [8].

\section{Goal-directed fluid therapy and Haemodynamic monitoring}

Goal-directed fluid therapy has become as essential concept in initial fluid resuscitation in severe burns and for critical care in general. Patients with severe burns require a large volume of fluid in resuscitation. This may not be well tolerated and may contribute to complications such as ileus, abdominal and extremity compartment syndromes, respiratory complications such as pulmonary oedema and adult respiratory distress syndrome (ARDS), and also generalized oedema [1]. Therefore, many studies have been conducted to identify feasible targets to guide fluid resuscitation. Furthermore, studies have shown that the vital signs and the urine output showed minimal variations after fluid resuscitation, however significant changes were noted in other parameters such as those measured by pulmonary artery catheterization (PAC). Therefore, vital signs alone was found to be inadequate to guide the adequacy of fluid resuscitation in critically ill patients [10].

Therefore, cardiac output has become an important parameter to guide volume resuscitation, however only less than $10 \%$ of specialised burns units utilise this parameter as PAC is required for its measurement [11]. Several studies have attempted to find non-invasive alternatives to PAC in fluid resuscitation based on goal directed therapy. However in the past, the applicability and validity of the novel alternatives in burn resuscitation have been questioned. Therefore, further studies were conducted for validation, identification of end points and the relevance in terms of improving outcomes [12]. Several techniques have been identified as useful or potentially useful monitoring parameters for guided fluid therapy in burns. Oesophageal echo-doppler monitoring was found to be a useful adjunct to clinical judgement in severe burns [13]. Transpulmonary thermodilution is one such noninvasive method that has been validated in burns [14]. Other methods include extra-vascular lung water, intrathoracic blood volume, pulse contour cardiac output (PiCCO), arterial waveform monitoring (LiDCO) devices and bioimpedance spectroscopy [1, 12, 15, 16] (Figure 1). However, certain studies have shown that use of arterial waveform monitoring devices such as LiDCO systems had lower fluid requirement than what was calculated by Parkland formula [12, 17]. Therefore, there is a discrepancy in the amount of volume between the Parkland formula and certain monitoring parameters (Figure 1) [12].

Although the majority of the studies showed the need of a more intensive initial fluid resuscitation compared to the Parkland formula to improve the pre-load factors such as cardiac index, venous oxygen saturation and oxygen delivery, 


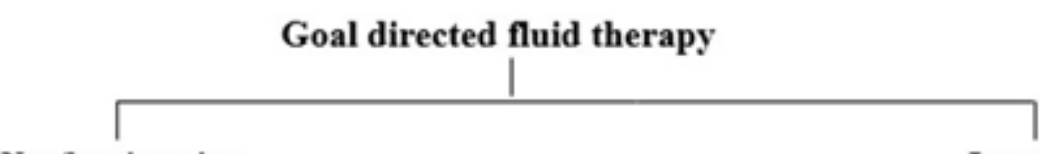

Non/less-invasive

Invasive

\begin{tabular}{|l|l|}
\multicolumn{1}{c|}{ Clinical } \\
\multicolumn{1}{c|}{\begin{tabular}{c}
\multicolumn{1}{c|}{ Adjuncts } \\
Vital signs
\end{tabular}} & $\begin{array}{l}\text { Transpulmonary thermodilution } \\
\text { Oesophageal echo-Doppler } \\
\text { Extra-vascular lung water } \\
\text { Intrathoracic blood volume } \\
\text { Pulse contour cardiac output (PiCCO) } \\
\text { Arterial waveform analysis (LiDCO) } \\
\text { Bioimpedance spectroscopy } \\
\text { Blood investigations: } \\
\text { Lactate levels } \\
\text { Lactate/pyruvate ratio } \\
\text { Base deficit } \\
\text { Microalbuminaemia }\end{array}$ \\
\hline
\end{tabular}

Pulmonary artery catheterization

(Gold Standard)

Figure 1. Goal directed fluid therapy in severe burns

Crystalloids

Balanced solutions

Ringer's lactate ${ }^{1}$

Ringer's Acetate ${ }^{1}$

Hypertonic saline ${ }^{2}$

${ }^{1}$ Recommended

2 Needs further studies before routine use

${ }^{3}$ Not recommended

Figure 2. Evidence for choice of fluid in burns resuscitation
Natural Colloids

Fresh frozen plasma ${ }^{2}$

Albumin ${ }^{2}$ 
the achievement of normovolaemia was challenging $[1,12]$. Therefore, normovolaemia may not be the main goal to achieve, and overzealous fluid resuscitation and trying to normalise the haemodynamic parameters should be avoided.

According to the recent systematic review on fluid resuscitation, the non-invasive alternatives to PAC have a reasonable role in initial fluid resuscitation in burns [12]. However, it is important to note that the studies included small sample sizes and based their conclusion on short-term haemodynamic parameters rather than long term outcome. To date, the impact of these monitoring parameters on patients' survival has not been determined. It is important to note that, most centres managing critically injured burn patients, especially in developing countries do not have these sophisticated resources to guide goal-directed fluid therapy techniques. Therefore, these centres reply on basic haemodynamic and biochemical parameters to guide fluid resuscitation.

Several metabolic factors have also been analysed in burn patients. Some variables such as lactate levels, the lactate/pyruvate ratio, the base deficit, and microalbuminuria were shown to be useful as prognostic markers and may be useful to guide initial resuscitation $[12,18]$. However, the evidence to support routine use of these parameters is not available [18]. Therefore, fluid resuscitation in severe burns should ideally be performed as goal-directed therapy with thermodilution methods as they have been validated in burns and are less invasive than PAC [12].

\section{Evidence on choice of fluid for resuscitation}

Crystalloids are the fluids of choice in initial burn resuscitation although, the volume retained in the intravascular compartment and the subsequent volume expansion is lower than colloids [8]. That is because the increased capillary permeability during the initial period will cause the colloids to pass through capillaries to the interstitial space and exert a deleterious oncotic effect and paradoxically reduce the intra-vascular fluid volume and worsen the oedema [19]. Despite the recent studies which claim that the increased vascular permeability is relatively short lasting (from 2-7 hours post-burn), the use of colloid in burns remains controversial [12].

According to the studies published on crystalloid-based fluid therapy in various types of critically ill patients, balanced solutions were superior to unbalanced crystalloids, due to the multiple adverse effects identified with saline solutions [20]. However, these studies include other critically ill patients and the studies on severe burns patients are limited and therefore, the question arises whether these can be extrapolated to burns patients. By definition, the Parkland formula is calculated for
Ringer's lactate (RL), and therefore has been the fluid of choice in burns [21]. The study by Oda et al compared RL with hypertonic lactated saline in severe burns and found that lactated saline group needed significantly lower amount of fluid and had lower peak abdominal and inspiratory pressures [22]. Furthermore, abdominal compartment syndrome was seen in $14 \%$ of patients in the hypertonic lactated saline group in comparison to $50 \%$ in the RL group [22]. Gille et al compared RL with Ringer's acetate and found Ringer's acetate to be superior in terms of lower organ failure assessment scores, requirement of smaller amount of colloids, packed cells and plasma infusion, shorter duration of hospital stay and mechanical ventilation. However, there was no difference in the volume of crystalloid infused and the mortality [23].

As balanced solutions have been proven to be superior for critically ill patients, Ringer's acetate seems most suitable for large replacement in burns patients based on the above study. However, further studies are needed to compare RL and Ringer's acetate in burns patients due to the methodological weaknesses in the available studies. Although hypertonic solutions may be useful in burn resuscitation, the analyses by the Cochrane systematic reviews, and USA guidelines have shown no clear benefit in terms of efficacy and therefore, further studies are required before routine use can be recommended [24].

Colloids are controversial in the management of burns especially after the recent warning regarding the use of Hydroxy-ethyl starch (HES) in critical ill patients including severe burns. Colloids contain macromolecules and possess a greater volume expanding effect than crystalloids [25]. They consist of either synthetic (HES and gelatine) or natural (plasma and albumin) components [25].

After the HES warning, the gelatins were the only available synthetic option for burns though the expansion capacity is inferior and short lasting (1 hour) [26]. However, there are no studies ensuring safety in burns patients and meta-analyses showed no advantages in using gelatin over crystalloids [26]. Therefore the use of gelatins in burns remains controversial and routine use is discouraged [26].

Several reviews have shown that HES use in critical care including burns had a higher risk of mortality and kidney injury as opposed to other resuscitation fluids [12]. However, due to the methodological concerns, a randomized trial comparing mixed resuscitation therapy (HES plus RL) and crystalloids alone (RL) was performed. In that study, no differences were found in the mortality, volume of fluid administered, or kidney injury between the groups [27].

Of the natural colloids, fresh frozen plasma has been used as 
plasma expanders however, the risk of transmission of infections hasdiscouraged its use in fluid resuscitation and it is mainly used when there is associated coagulopathy [28]. Also the activity based cost of fresh frozen plasma per each unit is around 410 USD in the United States [29] Although studies have shown benefits of using plasma in burns in terms of lesser resuscitation volume and lower abdominal compartment pressures, the sample size was very small. Therefore, larger studies are needed before considering routine use in burns patients $[12,28]$.

The use of albumin for fluid resuscitation in burns patients have been assessed by multiple studies and have shown conflicting results [12]. However, the recent meta-analysis of clinical trials in 2014, found that albumin was associated with a lower incidence of compartment syndrome and mortality [30]. Therefore, both albumin and plasma may be a suitable option for burn patients, however the lack of large scale clinical trials restrict their routine use [12] (figure 2).

\section{Management of coagulopathy in severe burns}

Similar to major trauma, coagulopathy is also associated with severe burns. The coagulopathy interferes with proper surgical debridement and repeated surgical debridement causes more bleeding and worsening coagulopathy. The coagulopathy is a combination of procoagulation, antifibrinolysis and impaired activity of anticoagulation systems of the body [31]. This process is associated with thromboembolic complications, multi organ failure and increase in morbidity. Moreover, coagulopathy was recently identified as an independent predictor of mortality within 28 days in patients with severe burns [32]. Pathophysiology of the coagulopathy includes dilution of factors by fluid resuscitation, hypothermia, endothelial injury, burn wound excision causing bleeding and activated systemic inflammatory response [33]. In burns, the evidence and recommendations for targets in management of coagulopathy are lacking. An international survey on coagulopathy in burn patents showed that although this entity is recognized, there is lack of specific treatment among physicians [34].

The management of coagulopathy includes, general measures for minimizing triggers and specific treatment depending on type of coagulopathy. Minimizing triggers includes, prevention of tissue hypoperfusion by goal directed fluid management, avoidance of hypothermia, and prevention of excessive blood loss during surgical treatment. Specific treatment and interventions may be directed towards anticoagulation or procoagulation depending on the type of coagulopathy. Treatment with antithrombin, activated protein $\mathrm{C}$, and tissue factor pathway inhibitor have not shown any benefit[35]. Newer options like recombinant activated factor VIIa have been studied in reduction of perioperative bleeding in burn wound excision but the associated arterial thrombotic events hinder its use [36] (Figure 3).

\section{Prevention and Treatment of Coagulopathy}

General measures

$$
\begin{aligned}
& \text { Goal directed fluid therapy } \\
& \text { Normothermia } \\
& \text { Haemostasis during surgery }
\end{aligned}
$$

\section{Specific measures depending on type of coagulopathy}

\author{
Antithrombin \\ Activated protein C \\ Tissue factor pathway inhibitor \\ Recombinant activated factor VIIa
}

Figure 3. Prevention and treatment of coagulopathy in severe burns 
All authors disclose no conflict of interest. The study was conducted in accordance with the ethical standards of the relevant institutional or national ethics committee and the Helsinki Declaration of 1975 , as revised in 2000 .

\section{References}

1. Lavrentieva A: Critical care of burn patients. New approaches to old problems. Burns 2016, 42(1):13-19.

https://doi.org/10.1016/j.burns.2015.04.009

2. Pham TN, Cancio LC, Gibran NS: American Burn Association practice guidelines burn shock resuscitation. Journal of Burn Care \& Research 2008, 29(1):257-266.

https://doi.org/10.1097/BCR.0b013e31815f3876

3. Nielson CB, Duethman NC, Howard JM, Moncure M, Wood JG: Burns: pathophysiology of systemic complications and current management. Journal of Burn Care \& Research 2017, 38(1):e469-e481.

https://doi.org/10.1097/BCR.00000000000003554.

4. Vercruysse GA, Alam HB, Martin MJ, Brasel K, Moore EE, Brown CV, Bettencourt A, Schulz J, Palmieri T, Haith L: Western Trauma Association critical decisions in trauma: Preferred triage and initial management of the burned patient. Journal of Trauma and Acute Care Surgery 2019, 87(5):1239-1243.

https://doi.org/10.1097/TA.0000000000002348

5. Azzopardi EA, McWilliams B, Iyer S, Whitaker IS: Fluid resuscitation in adults with severe burns at risk of secondary abdominal compartment syndrome-an evidence based systematic review. Burns 2009, 35(7):911-920.

https://doi.org/10.1016/j.burns.2009.03.001

6. Barrow RE, Jeschke MG, Herndon DN: Early fluid resuscitation improves outcomes in severely burned children. Resuscitation 2000, 45(2):91-96.

https://doi.org/10.1016/S0300-9572(00)00175-1

7. Ete G, Chaturvedi G, Barreto E: Effectiveness of Parkland formula in the estimation of resuscitation fluid volume in adult thermal burns. Chinese Journal of Traumatology 2019, 22(2):113-116.

https://doi.org/10.1016/j.cjtee.2019.01.006

8. Rae L, Fidler P, Gibran N: The physiologic basis of burn shock and the need for aggressive fluid resuscitation. Critical care clinics 2016, 32(4):491-505.

https://doi.org/10.1016/j.ccc.2016.06.001

9. Ahuja RB, Gibran N, Greenhalgh D, Jeng J, Mackie D, Moghazy A, Moiemen N, Palmieri T, Peck M, Serghiou M: ISBI practice guidelines for burn care. Burns 2016, 42(5):953-1021. https://doi.org/10.1016/j.burns.2016.05.013

10.Dries DJ, Waxman K: Adequate resuscitation of burn patients may not be measured by urine output and vital signs. Critical care medicine 1991, 19(3):327-329. https://doi.org/10.1097/00003246-199103000-00007

11.Holm C, Melcer B, Hörbrand F, von Donnersmarck GH, Mühlbauer W: Arterial thermodilution: an alternative to pulmonary artery catheter for cardiac output assessment in burn patients. Burns 2001, 27(2):161-166.

https://doi.org/10.1016/S0305-4179(00)00088-7

12. Guilabert P, Usúa G, Martín N, Abarca L, Barret J, Colomina M: Fluid resuscitation management in patients with burns: update. BJA: British Journal of Anaesthesia 2016, 117(3):284-296.

https://doi.org/10.1093/bja/aew266

13.Wang GY, Ma B, Tang HT, Zhu SH, Lu J, Wei W, Ge SD, Xia ZF: Esophageal echo-Doppler monitoring in burn shock resuscitation: are hemodynamic variables the critical standard guiding fluid therapy? The Journal of trauma 2008, 65(6):13961401. https://doi.org/10.1097/TA.0b013e3180f62643

14. Wurzer P, Branski LK, Jeschke MG, Ali A, Kinsky MP, Bohanon FJ, Hundeshagen G, Norbury WB, Williams FN, Kamolz L-P: Transpulmonary thermodilution versus transthoracic echocardiography for cardiac output measurements in severely burned children. Shock (Augusta, Ga) 2016, 46(3):249.

https://doi.org/10.1097/SHK.0000000000000627

15.Gong C, Zhang F, Li L, He F, Liu G-C, Zhu S-H, Wang G-Y, Xia $\mathrm{Z}$-f: The variation of hemodynamic parameters through $\mathrm{PiCCO}$ in the early stage after severe burns. Journal of Burn Care \& Research 2017,38(6):e966-e972. https://doi.org/10.1097/BCR.0000000000000533

16.Kenworthy P, Phillips M, Grisbrook TL, Gibson W, Wood FM, Edgar DW: An objective measure for the assessment and management of fluid shifts in acute major burns. Burns Trauma 2018, 6:3-3. https://doi.org/10.1186/s41038-017-0105-9

17.Tokarik M, Sjöberg F, Balik M, Pafcuga I, Broz L: Fluid Therapy LiDCO Controlled Trial-optimization of volume resuscitation of extensively burned patients through noninvasive continuous realtime hemodynamic monitoring LiDCO. Journal of Burn Care \& Research 2013,34(5):537-542.

https://doi.org/10.1097/BCR.0b013e318278197e

18. Andel D, Kamolz L-P, Roka J, Schramm W, Zimpfer M, Frey M, Andel H: Base deficit and lactate: early predictors of morbidity and mortality in patients with burns. Burns 2007, 33(8):973-978. https://doi.org/10.1016/j.burns.2007.06.016

19.Myburgh JA, Mythen MG: Resuscitation fluids. New England Journal of Medicine 2013, 369(13):1243-1251.

https://doi.org/10.1056/NEJMra1208627

20.Soni N: British Consensus Guidelines on Intravenous Fluid Therapy for Adult Surgical Patients (GIFTASUP): Cassandra's view. Anaesthesia 2009, 64(3):235. https://doi.org/10.1111/j.1365-2044.2009.05886_1.x

21.Greenhalgh DG: Burn resuscitation: the results of the ISBI/ABA survey. Burns 2010, 36(2):176-182. 
https://doi.org/10.1016/j.burns.2009.09.004

22.Oda J, Ueyama M, Yamashita K, Inoue T, Noborio M, Ode Y, Aoki Y, Sugimoto H: Hypertonic lactated saline resuscitation reduces the risk of abdominal compartment syndrome in severely burned patients. Journal of Trauma and Acute Care Surgery 2006, 60(1):64-71.

https://doi.org/10.1097/01.ta.0000199431.66938.99

23.Gille J, Klezcewski B, Malcharek M, Raff T, Mogk M, Sablotzki A, Taha H: Safety of resuscitation with Ringer's acetate solution in severe burn (VolTRAB)-an observational trial. Burns 2014, 40(5):871-880. https://doi.org/10.1016/j.burns.2013.11.021

24.Lewis SR, Pritchard MW, Evans DJ, Butler AR, Alderson P, Smith AF, Roberts I: Colloids versus crystalloids for fluid resuscitation in critically ill people. Cochrane Database of Systematic Reviews 2018(8). https://doi.org/10.1002/14651858.CD000567.pub7

25.Calota DR, Nitescu C, Florescu IP, Lascar I: Surgical management of extensive burns treatment using allografts. Journal of medicine and life 2012, 5(4):486-490.

26.Saw M, Chandler B, Ho K: Benefits and risks of using gelatin solution as a plasma expander for perioperative and critically ill patients: a meta-analysis. Anaesthesia and intensive care 2012, 40(1):17-32. https://doi.org/10.1177/0310057X1204000104

27.Béchir M, Puhan MA, Fasshauer M, Schuepbach RA, Stocker R, Neff TA: Early fluid resuscitation with hydroxyethyl starch 130/0.4 (6\%) in severe burn injury: a randomized, controlled, double-blind clinical trial. Critical Care 2013, 17(6):R299. https://doi.org/10.1186/cc13168

28. Yang L, Stanworth S, Hopewell S, Doree C, Murphy M: Is fresh-frozen plasma clinically effective? An update of a systematic review of randomized controlled trials (CME). Transfusion 2012, 52(8):1673-1686. https://doi.org/10.1111/j.1537-2995.2011.03515.x

29.Shander A, Ozawa S, Hofmann A: Activity-based costs of plasma transfusions in medical and surgical inpatients at a US hospital. Vox sanguinis 2016, 111(1):55-61.

https://doi.org/10.1111/vox.12386

30.Navickis RJ, Greenhalgh DG, Wilkes MM: Albumin in burn shock resuscitation: a meta-analysis of controlled clinical studies. Journal of Burn Care \& Research 2016, 37(3):e268-e278.

https://doi.org/10.1097/BCR.0000000000000201

31.Garcia-Avello A, Lorente J, Cesar-Perez J, García-Frade L, Alvarado R, Arevalo J, Navarro J, Esteban A: Degree of hypercoagulability and hyperfibrinolysis is related to organ failure and prognosis after burn trauma. Thrombosis research 1998, 89(2):59-64. https://doi.org/10.1016/S0049-3848(97)00291-0

32. Sherren P, Hussey J, Martin R, Kundishora T, Parker M, Emerson B: Acute burn induced coagulopathy. Burns 2013, 39(6):11571161. https://doi.org/10.1016/j.burns.2013.02.010

33.Lavrentieva A: Coagulopathy in burn patients: one part of a deadly trio. Burns 2015, 3(41):419-420.

https://doi.org/10.1016/j.burns.2014.11.009

34.Lavrentieva A, Depetris N, Kaimakamis E, Stella M, Berardino M: Perioperative use of specific coagulation factors in burn patients. an international survey. Intensive care medicine experimental 2015,3(1):A854.

https://doi.org/10.1186/2197-425X-3-S1-A854

35. Solà I, Gluud C, Lathyris D, Anand V, Martí-Carvajal AJ: Human recombinant protein $\mathrm{C}$ for severe sepsis and septic shock in adult and paediatric patients. The Cochrane database of systematic reviews 2012, 2012(12).

36. Martin JT, Alkhoury F, McIntosh BC, Fidler P, Schulz J: Recombinant factor VIIa: hemostatic adjunct in the coagulopathic burn patient. Eplasty 2009, 9. 